\title{
Keys and seats: Spatial response coding underlying the joint spatial compatibility effect
}

\author{
Kerstin Dittrich • Thomas Dolk • Annelie Rothe-Wulf • \\ Karl Christoph Klauer • Wolfgang Prinz
}

Published online: 30 July 2013

(C) Psychonomic Society, Inc. 2013

\begin{abstract}
Spatial compatibility effects (SCEs) are typically observed when participants have to execute spatially defined responses to nonspatial stimulus features (e.g., the color red or green) that randomly appear to the left and the right. Whereas a spatial correspondence of stimulus and response features facilitates response execution, a noncorrespondence impairs task performance. Interestingly, the SCE is drastically reduced when a single participant responds to one stimulus feature (e.g., green) by operating only one response key (individual go/no-go task), whereas a full-blown SCE is observed when the task is distributed between two participants (joint go/no-go task). This joint SCE (a.k.a. the social Simon effect) has previously been explained by action/task co-representation, whereas alternative accounts ascribe joint SCEs to spatial components inherent in joint go/no-go tasks that allow participants to code their responses spatially. Although increasing evidence supports the idea that spatial rather than social aspects are responsible for joint SCEs emerging, it is still unclear to which component(s) the spatial coding refers to: the spatial orientation of response keys, the spatial orientation of responding agents, or both. By varying the spatial orientation of the responding agents (Exp. 1) and of the response keys (Exp. 2), independent of the spatial orientation of the stimuli, in the present study we found joint SCEs only when both the seating and the response key alignment matched the stimulus alignment. These results
\end{abstract}

K. Dittrich • A. Rothe-Wulf $・$ K. C. Klauer

Department of Psychology, Albert-Ludwigs-Universität Freiburg,

Freiburg, Germany

T. Dolk $\cdot$ W. Prinz

Department of Psychology, Max Planck Institute for Human

Cognitive and Brain Sciences, Leipzig, Germany

K. Dittrich $(\bowtie)$

Institut für Psychologie, Albert-Ludwigs-Universität Freiburg,

79085 Freiburg, Germany

e-mail: dittrich@psychologie.uni-freiburg.de provide evidence that spatial response coding refers not only to the response key arrangement, but also to the-often neglected - spatial orientation of the responding agents.

Keywords Simon effect · Action co-representation · Joint action · Spatial compatibility task · Dimensional overlap . Spatial response coding

Humans as social beings rarely carry out their tasks and actions in isolation. Often they work together with or in the context of other people. To accomplish this, mechanisms to coordinate each others' actions are required (for recent discussions of prerequisites for joint action, see Knoblich, Butterfill, \& Sebanz, 2011; Prinz, 2012; Sebanz, Bekkering, \& Knoblich, 2006; Vesper, Butterfill, Knoblich, \& Sebanz, 2010). Scrutinizing the underlying mechanisms of such complex processes, in previous experimental approaches, cognitive tasks have been developed that can be performed either alone or together with another person (e.g., Atmaca, Sebanz, \& Knoblich, 2011; Atmaca, Sebanz, Prinz, \& Knoblich, 2008; Philipp \& Prinz, 2010; Sebanz, Knoblich, \& Prinz, 2003). The most prominent of these cognitive tasks is a spatial compatibility task, also known as the Simon task (Simon, 1969, 1990; see $\mathrm{Lu} \&$ Proctor, 1995, for an overview). In the standard, forced two-choice Simon task, participants are asked to respond to nonspatial stimulus features (e.g., red and green stimuli) that randomly appear to the left and to the right by pressing either one of two spatially aligned response keys (e.g., the left key in response to green and the right key in response to red). Even though the spatial location of the stimulus is completely task-irrelevant, response execution is impaired when the stimulus position and response side do not correspond spatially (incompatible trials), relative to trials in which both correspond spatially (compatible trials), a phenomenon known as the spatial compatibility effect (SCE) or Simon effect (see Hommel, 2011, for a review). A well-known account of SCEs is the dimensional overlap model of 
Kornblum, Hasbroucq, and Osman (1990; for other accounts explaining SCEs, see De Jong, Liang, \& Lauber, 1994; Eimer, Hommel, \& Prinz, 1995; Hommel, Müsseler, Aschersleben, \& Prinz, 2001; see Lu \& Proctor, 1995, for an overview). According to the dimensional overlap model, the features of the stimulus ( $\mathrm{S}$ ) and response (R) dimension overlap when they are similar (e.g., when both the stimuli and the response keys are arranged on a left-right dimension, the spatial features of the stimulus and the response dimension overlap). When a stimulus with a spatial feature appears (e.g., a stimulus pointing to the left), the dimensional overlap of spatial S-R features leads to an automatic activation of a corresponding spatial response (e.g., pressing the left key) that interferes with the required response, in the case of incompatible trials.

To investigate the influence of acting together as opposed to performing the Simon task alone, Sebanz et al. (2003) introduced a new joint go/no-go task setting - the so-called social Simon paradigm - by distributing the two response alternatives across two participants (e.g., one participant responded to red stimuli by pressing the left response key, and the other participant responded to green stimuli by pressing the right response key). This experimental setting of joint task performance elicited an SCE (a joint SCE, a.k.a. the social Simon effect; Sebanz et al., 2003), which is particularly surprising, given that SCEs are remarkably reduced or even absent when participants respond to only one task-relevant stimulus feature (e.g., only to red stimuli) by exclusively operating either the left or the right response button in an individual go/no-go task (Hommel, 1996a; Liepelt, Wenke, Fischer, \& Prinz, 2011; Shiu \& Kornblum, 1999). ${ }^{1}$ On the basis of these initial findings, Sebanz et al. (2003) considered joint SCEs as evidence for action co-representation: Following their account, participants not only form cognitive representations of their own action, but also of the coactor's action. This assumption rests on the hypothesis that perceived, other-generated actions and executed, self-generated actions are represented in a functionally equivalent way (e.g., Hommel et al., 2001; Prinz, 1990, 1997); thus, not only the actions themselves, but also the spatial dimension of the two response alternatives, are assumed to be represented, leading to an S-R overlap similar to that in forced two-choice tasks (Sebanz et al., 2003). Meanwhile, a growing number of studies have supported Sebanz et al.'s (2003) results and their assumption of action/task co-representation (see also Kiernan, Ray, \& Welsh, 2012; Sebanz, Knoblich, \& Prinz,

\footnotetext{
${ }^{1}$ To ease readability, we will discuss forced two-choice spatial compatibility tasks and (joint/individual) go/no-go spatial compatibility tasks as "forced two-choice tasks" and "(joint/individual) go/no-go tasks," although we are aware that a number of forced two-choice and go/no-go tasks that do not belong to the class of spatial compatibility tasks also exist.
}

2005; Welsh, Kiernan, Neyedli, Ray, Pratt, Potruff, \& Weeks, 2013) by showing that joint SCEs are modulated by several social factors; for example, the occurrence and size of joint SCEs depended on whether participants performed the joint go/no-go task with another intentional agent or with a computer, puppet, or robot (e.g., Müller, Brass, Kühn, Tsai, Nieuwboer, Dijksterhuis, \& van Baaren, 2011; Stenzel, Chinellato, Tirado Bou, del Pobil, Lappe, \& Liepelt, 2012; Tsai \& Brass, 2007; Tsai, Kuo, Hung, \& Tzeng, 2008).

Recently, however, an increasing number of studies have challenged the idea of action/task co-representation by demonstrating that joint SCEs can be elicited via social and nonsocial events (e.g., by another agent or inanimate object; Dittrich, Rothe, \& Klauer, 2012; Dolk, Hommel, Colzato, Schütz-Bosbach, Prinz, \& Liepelt, 2011; Dolk, Hommel, Prinz, \& Liepelt, 2013; Dolk, Liepelt, Prinz, \& Fiehler, 2013; Guagnano, Rusconi, \& Umiltà, 2010). To simplify matters, we will term this approach the spatial-coding account in the remainder of this article, although the ideas of spatial coding formulated in previous works have focused on different aspects. ${ }^{2}$ In contrast to the social interpretation of joint SCEs, the spatial-coding account ascribes joint SCEs to spatial components inherent in joint go/no-go tasks that allow participants to code their responses spatially, enabling the discrimination of cognitive representations related to one's own and to othergenerated actions, thereby ensuring proper task performance (Dolk, Hommel, et al., 2013; Dolk, Liepelt, Villringer, Prinz, \& Ragert, 2012; Hommel, Colzato, \& van den Wildenberg, 2009; Liepelt et al., 2011). Thus, it is assumed that, similar to forced two-choice tasks, the spatial coding of responses leads to overlapping spatial S-R features, explaining faster responses in cases of S-R correspondence (compatible trials) and impaired performance in cases of S-R noncorrespondence (incompatible trials). Although increasing evidence is accruing for the spatial-coding account, it is still unclear to which spatial component the spatial coding refers to, as joint go/no-go tasks consist of at least two distinct spatial components - the spatial orientation of the response keys, and the spatial orientation of the coacting participants - that might influence the spatial coding of responses either independently or in conjunction.

In the present work, we aim to provide further empirical evidence for the spatial-coding account as an alternative explanation of joint SCEs, by specifying this account and by

\footnotetext{
${ }^{2}$ Whereas the spatial response coding account proposed by Dittrich et al. (2012) is concerned with rather basal (bottom-up) mechanisms (the task set; e.g., the seating position is assumed to induce a specific coding of responses), the referential coding account introduced by Dolk and colleagues (Dolk et al., 2011; Dolk, Hommel, et al., 2013) focuses on more global mechanisms (spatial response coding is induced to discriminate between action alternatives). Therefore, the accounts are compatible and complementary to each other, but focus on rather different aspects.
} 
identifying the spatial component(s) influencing response coding. This appears particularly relevant because several studies supporting the spatial-coding account have examined SCEs only in individual go/no-go tasks (e.g., Dittrich et al., 2012, Exp. 1; Dolk et al., 2011, Exp. 3; Dolk, Hommel, et al., 2013). By using a horizontal version (left-right alignment of the stimuli and response keys) and a vertical version (topbottom alignment of the stimuli and response keys) of a joint go/no-go task, Dittrich et al. (2012) provided evidence for the spatial-coding account in joint action. Although they found SCEs for both versions in forced two-choice conditions, no joint SCE was apparent when participants sat to the left and right of each other and responded to vertically aligned stimuli with vertically arranged response keys. However, joint SCEs were observed in the horizontal version of a joint go/no-go task in which the stimuli, response keys, and seating arrangement were horizontally aligned. In contrast to the action/task co-representation account, which predicts joint SCEs in any condition in which an equivalent forced two-choice condition would reveal SCEs, a spatial-coding account can explain the observed result pattern: The horizontal seating alignment led participants to code their responses as left or right, but these response codes did not match with the vertical stimulus arrangement in the vertical version of the task.

Dittrich et al.'s (2012) results not only provided evidence for the spatial-coding account in general, but they also suggested that spatial response coding refers (also) to the spatial relation of coacting participants. As several researchers developing and investigating the spatial-coding account have concentrated on the spatial relation of response keys or the spatial relation of alternative action events (Dolk et al., 2011; Dolk, Hommel, et al., 2013; Dolk, Liepelt, et al., 2013; but see Guagnano et al., 2010), the spatial relation of participants is an intriguing, so far often neglected, influencing factor on spatial response coding and in turn on joint SCEs, that will be further examined in the present work. Recent research already suggests that the role of responding agents might be a relevant factor for joint compatibility effects: Philipp and Prinz (2010) asked participants to respond to the color of a diamond that was placed on a task-irrelevant photo of the participant's face, a coacting friend's face, or an unknown face. Joint compatibility effects occurred along with faster responses in trials in which the task-irrelevant photo displayed the participants' own face; these results were independent of the specific response mode (participants responded to the colors by either naming their own name, their friend's name, or by pressing the assigned response key). Philipp and Prinz concluded that the responding agents, and not the specific response mode, are what induce joint compatibility effects. Even though Philipp and Prinz used a nonspatial task that is not readily transferable to spatial compatibility tasks, their results highlighted the role of the agents for the occurrence and modulation of joint compatibility effects that might also play a significant role for the occurrence of joint SCEs (see also Hommel et al., 2009; Liepelt, Wenke, \& Fischer, 2013; Wenke, Atmaca, Holländer, Liepelt, Baess, \& Prinz, 2011).

Based on this accumulative evidence, spatial response coding might not only refer to the spatial alignment of the response keys $\left(R_{\mathrm{K}}\right)$ but also to the spatial alignment of coacting agents $\left(R_{\mathrm{A}}\right)$ as a second, often neglected aspect of the response dimension in joint go/no-go tasks. However, since $R_{\mathrm{A}}$ and $R_{\mathrm{K}}$ have so far been confounded in previous studies examining joint SCEs (typically, both are horizontally aligned; e.g., Sebanz et al., 2003; Sebanz et al., 2005), it is still unknown which spatial component $\left(R_{\mathrm{A}}\right.$ or/and $\left.R_{\mathrm{K}}\right)$ is the relevant one that has to match with the spatial stimulus alignment $(S)$ for joint SCEs to occur. Theoretically, three possibilities can be distinguished: First, it is possible that a spatial match of $S$ and $R_{\mathrm{K}}$ is necessary for joint SCEs to occur; indicating joint SCEs to be independent of $R_{\mathrm{A}}$. Second, $S$ might have to match with $R_{\mathrm{A}}$ to obtain joint SCEs; in this case, joint SCEs would be independent of $R_{\mathrm{K}}$. Third, it is possible that $S, R_{\mathrm{A}}$, and $R_{\mathrm{K}}$ all have to match to obtain joint SCEs. ${ }^{3}$ On the basis of the existing results, only one possibility - the first one - can be ruled out: Dittrich et al. (2012) avoided the confounding of $R_{\mathrm{A}}$ and $R_{\mathrm{K}}$ by varying the dimensions not only horizontally, but also vertically. As described above, they did not find joint SCEs in a condition in which left and right sitting participants had to respond to vertically aligned stimuli with vertically aligned response keys in a joint go/no-go task $\left(S=R_{\mathrm{K}} \neq R_{\mathrm{A}}\right)$.

Taking the two remaining possibilities into account $\left(S=R_{\mathrm{A}} \neq\right.$ $R_{\mathrm{K}} ; S=R_{\mathrm{A}}=R_{\mathrm{K}}$ ) spatial response coding may refer to the nature of the (spatial) relation of coacting participants, either exclusively, or in conjunction with spatial response key alignment. Two experiments were conducted to provide further evidence for the spatial-coding account as an alternative explanation of joint SCEs by (a) verifying that spatial response coding does indeed refer to the spatial relation of coacting participants (Exp. 1) and by (b) scrutinizing to what extent spatial response coding is determined by a conjunction of spatial features referring to keys and seats (Exp. 2). If spatial response coding does refer to the spatial relation of coacting participants (either exclusively or in addition to the spatial relation of response keys), it should be possible to obtain joint SCEs in a vertical spatial compatibility task when not only $R_{\mathrm{K}}$ (as in the experiment reported by Dittrich et al., 2012) but also $R_{\mathrm{A}}$ is vertically aligned $\left(S=R_{\mathrm{K}}=R_{\mathrm{A}}\right.$; Exp. 1). Having confirmed this prediction, Experiment 2 investigated the potential exclusiveness of $R_{\mathrm{A}}$ for spatial response coding.

\footnotetext{
${ }^{3}$ Note that, according to the dimensional overlap model (Kornblum et al., $1990)$, a match of only $R_{\mathrm{A}}$ and $R_{\mathrm{K}}\left(R_{\mathrm{A}}=R_{\mathrm{K}} \neq S\right)$ cannot be responsible for joint SCEs because there is no possibility of a stimulus-response overlap, and thus no SCEs are expected to occur.
} 
Specifically, it was examined whether spatial response coding (and thus joint SCEs) is only based on $R_{\mathrm{A}}$ or additionally on $R_{\mathrm{K}}$.

\section{Experiment 1}

Dittrich et al. (2012) found that joint SCEs were not observable when the stimuli $(S)$ and response keys $\left(R_{\mathrm{K}}\right)$ were vertically aligned while coacting participants $\left(R_{\mathrm{A}}\right)$ sat next to each other (i.e., horizontal seating alignment; $S=R_{\mathrm{K}} \neq R_{\mathrm{A}}$ ). If joint SCEs are based on spatial response coding referring to $R_{\mathrm{A}}$, it should be possible to obtain joint SCEs with vertically arranged stimuli if $R_{\mathrm{A}}$ is also vertically aligned. To test this prediction, we asked pairs of participants to perform a joint go/no-go task with vertically aligned stimuli. Two between-subjects conditions were implemented: In a first condition, participants sat next to each other and responded to vertically aligned stimuli with vertically arranged response keys $\left(S=R_{\mathrm{K}} \neq R_{\mathrm{A}}\right)$; we term this condition the horizontal condition. In contrast to Dittrich et al. (2012) who placed the response pad with vertically arranged keys flat on the table, we put the response pad in an upright position, which we presume to function as a stronger cue for $R_{\mathrm{K}}$ (or the features thereof) to be perceived vertically. This was to enhance the chance for joint SCEs to emerge even though agents' seating alignment differs from the stimulus and response key alignment. Thus, the experimental setup chosen in this condition provided an even stronger test for the assumption that spatial response coding refers to $R_{\mathrm{A}}$, relative to the experimental setup used by Dittrich et al. (2012). The second condition differed from the first condition only with regard to the participants' seating position, which was vertically aligned ( $S=R_{\mathrm{K}}=R_{\mathrm{A}}$ ); we term this condition the vertical condition. In contrast to the horizontal condition, the vertical seating arrangement should allow participants to code their responses vertically, thereby leading to an overlap of the vertical stimulus dimension and vertically coded responses, thus leading to a joint SCE.

\section{Method}

Participants A group of 48 right-handed University-ofFreiburg students ( 34 female, 14 male; mean age $=22.3$ years, $S D=3.1$ ) with different majors participated for course credit or as paid volunteers. All participants reported normal or corrected-to-normal vision. They were randomly assigned to either the horizontal or the vertical condition and participated in same-gender pairs.

Materials and apparatus The stimuli were adapted from those of Tsai, Kuo, Jing, Hung, and Tzeng (2006; see Fig. 1): A white-framed upright rectangle (subtending a solid angle of approximately $3.3^{\circ} \times 8.5^{\circ}$ in width and height in terms of visual angle) containing three unfilled white circles (a solid angle of approximately $1.0^{\circ}$ in radius and $0.5^{\circ}$ in distance between the circles) was presented vertically on a blue background in the center of the computer screen with $100-\mathrm{Hz}$ refresh rate during all blocks. The unfilled white circles were presented in the upper, middle, or lower part of the rectangle. Targets were either a red or a green filled circle replacing one of the three unfilled white circles in each trial. In both the vertical and horizontal condition, participants responded with one single upright response pad consisting of two vertically aligned response keys. The pad position varied depending on condition: In the horizontal condition, the response pad was placed in the middle of the table in front of the computer screen; in the vertical condition, the response pad was positioned on the right side of both participants, equally distant from each participant (see Fig. 1). ${ }^{4}$ All participants entered their responses with their right index fingers.

Procedures Participants worked through two practice blocks of 60 trials per block, to familiarize themselves with the task, and four experimental blocks of 126 trials per block. Each trial started with the presentation of the white rectangle and three unfilled white circles for $400 \mathrm{~ms}$, followed by the target circle of either red or green color. The target circle remained visible for $150 \mathrm{~ms}(3,000 \mathrm{~ms}$ in the first practice block) or until a response was recorded. ${ }^{5}$ Reaction time was measured from the onset of the target display. Participants had a time period of $600 \mathrm{~ms}(3,000 \mathrm{~ms}$ in the first practice block) to respond. Responses exceeding this time period were recorded as omissions. The intertrial interval was $500 \mathrm{~ms}$. Error feedback was displayed for $500 \mathrm{~ms}$ when the response was false ("Fehler!" [error!]) or too slow ("Zu langsam!" [too slow!]). The feedback appeared on the respective side of the participant who made a false response (in the horizontal condition, the feedback appeared either on the left or right side of the upright rectangle; in the vertical condition, the feedback appeared either above or below the upright rectangle).

Participants in the horizontal condition were seated next to each other in front of the computer screen. The upright key pad was positioned in front of them (see Fig. 1, left panel). We counterbalanced whether the left or the right participant had to press the lower or the upper key, and also counterbalanced

\footnotetext{
${ }^{4}$ We chose to place the response pad on the right side of the participants in the vertical condition because we wanted participants to respond on the same response pad; because participants sat in front of and behind one another, it was impossible to place the response pad centrally. Note, however, that according to the spatial-coding account, the lateral placement of the response pad would, if anything, be expected to reduce the joint SCE (because the perception of the response dimension as being vertical would be blurred by the simultaneous activation of a left-right response dimension), instead of artificially increasing the effect. According to an account of shared task representation, the placement of the response pad should not have any effect.

${ }^{5}$ To familiarize participants with the task, the timing in the first practice block was slower than in the following practice and experimental blocks.
} 

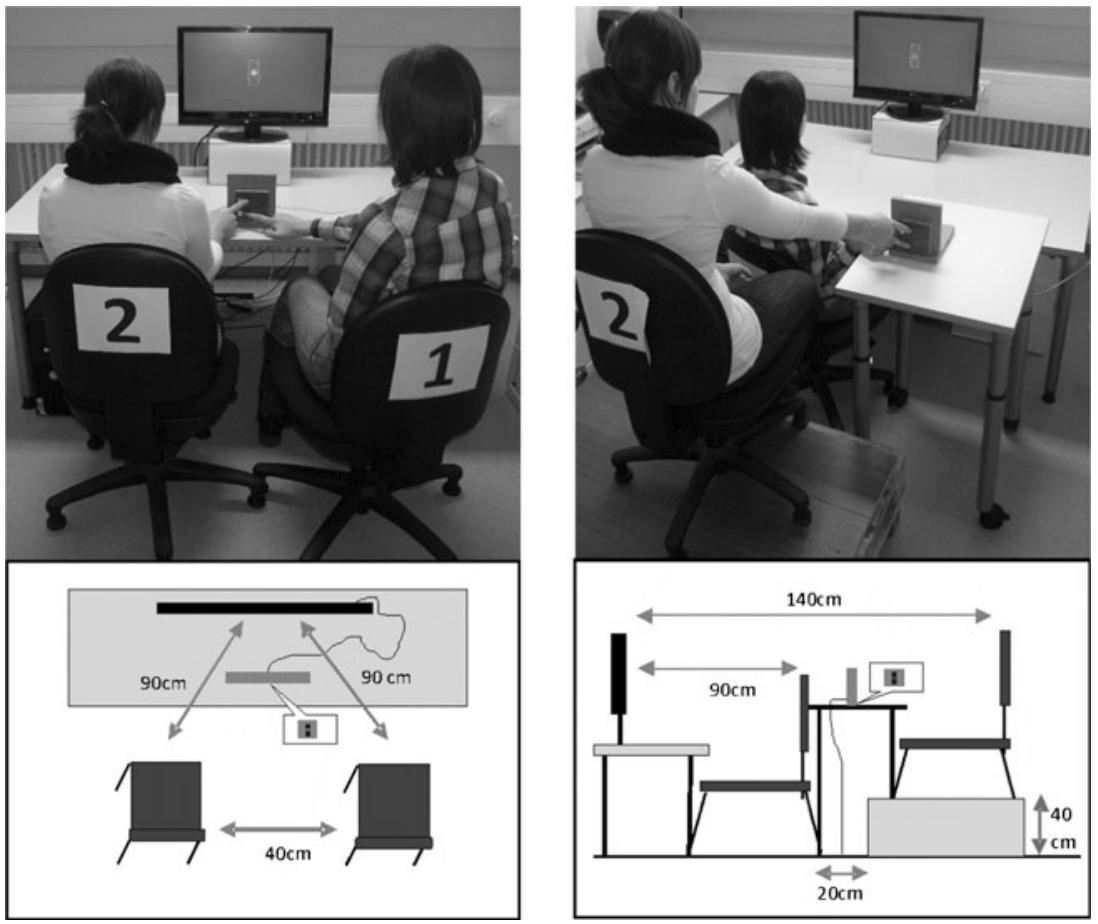

Fig. 1 The experimental setup used in Experiment 1. Participants either performed the spatial compatibility task seated next to each other (horizontal condition, left panel) or in front of and behind each other (vertical condition, right panel)

whether the left or the right participant responded to red or green circles. In the vertical condition, participants sat in front of and behind one another. To emphasize the vertical alignment, the chair for the "upper" participant sitting in the back was positioned on an elevated platform of approximately $40 \mathrm{~cm}$ in height (see Fig. 1, right panel). The "upper" participant always responded with the upper key, whereas the "lower" participant reacted by pressing the lower key. Whether the "upper" or the "lower" participant responded to red or green circles was counterbalanced. All participants were instructed to respond only to one color with the respective key press. To avoid the instructions biasing participants' response codings (e.g., Dittrich \& Klauer, 2012; Eder \& Rothermund, 2008), words like "right" and "left" or "upper" and "lower" were not mentioned during the experiment. Instead, numbers (e.g., Participant 1 and Participant 2, Response Key 1 and Response Key 2) were used. The experiment lasted approximately $30 \mathrm{~min}$.

\section{Results}

Trials were coded as compatible (stimulus-response correspondence), incompatible (stimulus-response noncorrespondence), and neutral (the imperative stimulus was presented in the middle), according to the spatial attribute of the target and the required response. Mean response latencies and mean error rates for compatible, incompatible, and neutral trials, as well as SCEs (reaction time and error difference between incompatible and compatible trials) are presented separately for both conditions (vertical, horizontal) in Table 1. Response latencies and error rates were submitted to $3 \times 2$ analyses of variance with the within-subjects factor compatibility (compatible, incompatible, neutral) and the between-subjects factor condition (vertical vs. horizontal). For reaction time, analyses revealed a main effect of compatibility, $F(2,92)=39.94, p<.01, \eta_{\mathrm{p}}^{2}=.47$, indicating faster responses for compatible than for incompatible trials (see Table 1 for details). As expected, joint SCEs differed between conditions, as reflected by a significant interaction of compatibility and condition, $F(2,92)=3.40, p=.04, \eta_{\mathrm{p}}{ }^{2}=.07$. Followup $t$ tests were conducted to interpret the two-way interaction of compatibility and condition. As predicted, the joint SCE was not significant in the horizontal condition $(t<1)$, but the vertical condition revealed a significant joint SCE, $t(23)=2.59, p=.02$, $d=0.53$ (see Table 1 ). ${ }^{6}$ We observed no main effect of condition, indicating that both the vertical and the horizontal condition did not differ in the overall reaction time, $F<1$.

Analyses of the error rates revealed a main effect of compatibility, $F(2,92)=3.76, p=.03, \eta_{\mathrm{p}}{ }^{2}=.08$, indicating less errors for compatible than for incompatible trials (see Table 1 for details). However, follow-up $t$ tests indicated that the joint SCE was neither significant in the horizontal condition, $t(23)=$ $1.49, p=.15, d=0.30$, nor in the vertical condition, $t(23)=2.01$, $p=.06, d=0.41$ (see also Table 1). Furthermore, a significant main effect of condition indicated that participants in the vertical condition responded to all kinds of trials more accurately than participants in the horizontal condition, $F(1,46)=5.71, p=.02$,

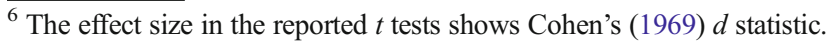


Table 1 Experiment 1: Mean response latencies (in milliseconds), error rates (as percentages), and standard deviations for compatible, neutral, and incompatible trials, along with spatial compatibility effects (SCEs: incompatible trials minus compatible trials), as a function of condition

\begin{tabular}{|c|c|c|c|c|c|c|c|c|}
\hline \multirow[b]{3}{*}{ Condition } & \multicolumn{6}{|c|}{ Spatial Compatibility } & & \\
\hline & \multicolumn{2}{|c|}{ Compatible } & \multicolumn{2}{|c|}{ Neutral } & \multicolumn{2}{|c|}{ Incompatible } & \multicolumn{2}{|c|}{ SCE } \\
\hline & $M$ & $S D$ & $M$ & $S D$ & $M$ & $S D$ & $M$ & $S D$ \\
\hline \multicolumn{9}{|c|}{ Response Latencies } \\
\hline Horizontal & 334 & 28 & 325 & 29 & 335 & 24 & 1 & 12 \\
\hline Vertical & 334 & 37 & 322 & 38 & 341 & 43 & $7^{*}$ & 13 \\
\hline \multicolumn{9}{|l|}{ Error Rates } \\
\hline Horizontal & 2.3 & 2.3 & 2.7 & 2.2 & 3.0 & 2.4 & 0.7 & 2.5 \\
\hline Vertical & 1.0 & 1.4 & 2.3 & 1.7 & 1.6 & 1.7 & 0.6 & 1.6 \\
\hline
\end{tabular}

${ }^{*} p<.05$.

$\eta_{\mathrm{p}}{ }^{2}=.11$, whereas the interaction of compatibility and condition was not significant in the error rates, $F=1.39$.

\section{Discussion}

Our first experiment tested the prediction that joint SCEs are based on spatial response coding referring to $R_{\mathrm{A}}$. This was confirmed by the SCE observed in the reaction times of the vertical condition, in which all dimensions were vertically aligned $\left(S=R_{\mathrm{K}}=R_{\mathrm{A}}\right.$ ). Replicating previous results (Dittrich et al., 2012), the vertical alignment of response keys alone is not sufficient to elicit joint SCEs in a joint vertical go/no-go task as indicated by the nonsignificant joint SCE in the horizontal condition $\left(S=R_{\mathrm{K}} \neq R_{\mathrm{A}}\right.$ ). Moreover, by placing the response pad in an upright position, and thus emphasizing the vertical orientation of $R_{\mathrm{K}}$ more intensely than by placing the pad flat on the table (see Dittrich et al., 2012), the present experiment provided an even stronger test for the assumption that $S=R_{\mathrm{K}} \neq R_{\mathrm{A}}$ is not sufficient to induce joint SCEs. This result is in line with previous research, demonstrating that response pad orientation has little influence on SCEs in forced two-choice tasks (Vu, Proctor, \& Pick, 2000). Moreover, the joint SCE in the vertical condition was of a similar size as joint SCEs observed by Dittrich et al. (2012) in a joint go/no-go task with horizontally aligned stimuli, response keys, and seating position that was, in all other regards, comparable in used materials and procedures (all SCEs ranged between 5-7 ms). This pattern of results found in joint go/no-go tasks is similar to what has been found in forced two-choice tasks: Previous research demonstrated that SCEs in horizontal and vertical forced two-choice tasks are of similar size (Proctor, Vu, \& Nicoletti, 2003; Vu, Pellicano, \& Proctor, 2005), at least when the horizontal dimension was not made more salient by instructions (for a detailed discussion of this issue, see Hommel, 1996b).

On the basis of the present results, we can further confirm our prediction that joint SCEs are not necessarily based on shared action/task co-representations. Given that the action/ task co-representation account (Sebanz et al., 2003; Sebanz et al., 2005) assumes that both one's own and the coactor's action are represented in a functionally equivalent way, this representation of the full $\mathrm{S}-\mathrm{R}$ set should lead to a feature overlap of the S-R dimensions irrespective of the spatial orientation of the two coacting individuals. However, by demonstrating a joint SCE in the vertical but not in the horizontal condition, the present results clearly falsify this assumption. Instead, the results are in line with a spatialcoding account (Dolk et al., 2011; Dolk, Hommel, et al., 2013; Dittrich et al., 2012). Accordingly, the vertical seating arrangement prompted participants to code their responses vertically leading to an overlap of the vertical stimulus dimension and the vertically coded response, thus leading to a joint SCE. The horizontal seating arrangement in contrast led participants to code their responses horizontally, counteracting a vertical $\mathrm{S}-R_{\mathrm{K}}$ overlap and thus, preventing a joint SCE to emerge. So far, we found evidence for the assumption that joint SCEs are based on spatial response coding referring to the seating position of the coacting participants, whereas the role of the spatial orientation of response keys for spatial response coding remains unclear. Therefore, a second experiment was conducted to investigate whether spatial response coding refers exclusively to $R_{\mathrm{A}}$ or also to $R_{\mathrm{K}}$.

\section{Experiment 2}

In our first experiment, we found a joint $\mathrm{SCE}$ when $S, R_{\mathrm{A}}$, and $R_{\mathrm{K}}$ were all vertically aligned but we did not find a joint SCE when spatial features of the stimulus dimension matched only the response key alignment $\left(S=R_{\mathrm{K}} \neq R_{\mathrm{A}}\right)$. From these findings, however, it is still unclear whether the disappearance of the joint SCE in the horizontal condition was due to the spatial dis-alignment of coacting participants toward the stimulus dimension $\left(S \neq R_{\mathrm{A}}\right)$ or toward the stimuli and the response keys $\left(S=R_{\mathrm{K}} \neq R_{\mathrm{A}}\right)$. In other words, it remains to be seen whether spatial response coding refers exclusively to the seating alignment of coacting participants or, additionally, also to the spatial alignment of response keys. To disentangle both possibilities, we conducted an experiment with one condition in which $S, R_{\mathrm{A}}$, and $R_{\mathrm{K}}$ all matched and one condition in which only $S$ and $R_{\mathrm{A}}$ matched. The first condition was an exact replication of the vertical condition used in Experiment 1 ( $S=R_{\mathrm{A}}=R_{\mathrm{K}}$; we term this the vertical condition). The second condition differed only with regard to the response key 
alignment, which was horizontal $\left(S=R_{\mathrm{A}} \neq R_{\mathrm{K}}\right.$; we term this the horizontal condition). If spatial response coding refers to $R_{\mathrm{A}}$ only, joint SCEs should be observable in both conditions. If, however, spatial response coding refers not exclusively to $R_{\mathrm{A}}$ but also to $R_{\mathrm{K}}$, joint SCEs should only be observed in the vertical condition, in which both $R_{\mathrm{A}}$ and $R_{\mathrm{K}}$ induce a vertical coding of responses.

\section{Method}

Participants A group of 48 right-handed University-ofFreiburg students (32 female, 16 male; mean age $=23.1$ years, $S D=5.9$ ) with different majors participated for course credit or as paid volunteers. All participants had normal or correctedto-normal vision, were tested in same-gender pairs, and were randomly assigned to one of two experimental conditions defined by response key alignment (horizontal vs. vertical).

Materials and procedures The materials and procedures were identical to those of Experiment 1, except for the following differences. The seating position for all participants was vertically aligned (see Fig. 2). The only difference between the two groups was the response key alignment. In one group, the response key alignment was vertical (Fig. 2, right panel). This condition was identical to the vertical condition of Experiment 1. In the second group, response keys were horizontally aligned (Fig. 2, left panel); it was counterbalanced whether the "upper" participant or the "lower" participant pressed the right or left key.

Results

Mean response latencies and mean error rates for compatible, incompatible, and neutral trials, as well as SCEs, are presented in Table 2, separately for the vertical and the horizontal condition.

Response latencies and error rates were submitted to $3 \times 2$ analyses of variance with the within-subjects factor compatibility (compatible, incompatible, neutral) and the betweensubjects factor condition (vertical vs. horizontal). Analyses of reaction time revealed a main effect of compatibility, $F(2$, $92)=26.27, p<.01, \eta_{\mathrm{p}}{ }^{2}=.36$, indicating faster responses for compatible than for incompatible trials (see Table 2 for details). More importantly, SCEs differed between both conditions as reflected by a significant interaction of compatibility and condition, $F(2,92)=3.55, p=.03, \eta_{\mathrm{p}}{ }^{2}=.07$. Follow-up $t$ tests were conducted to interpret the two-way interaction of compatibility and condition in reaction time: Although a significant joint SCE was found in the vertical condition, $t(23)=2.22, p=.04, d=0.45$, this effect was not significant in the horizontal condition $(t<1)$. We observed no main effect of condition, indicating that both the vertical and the horizontal condition did not differ in the overall reaction time, $F<1$.
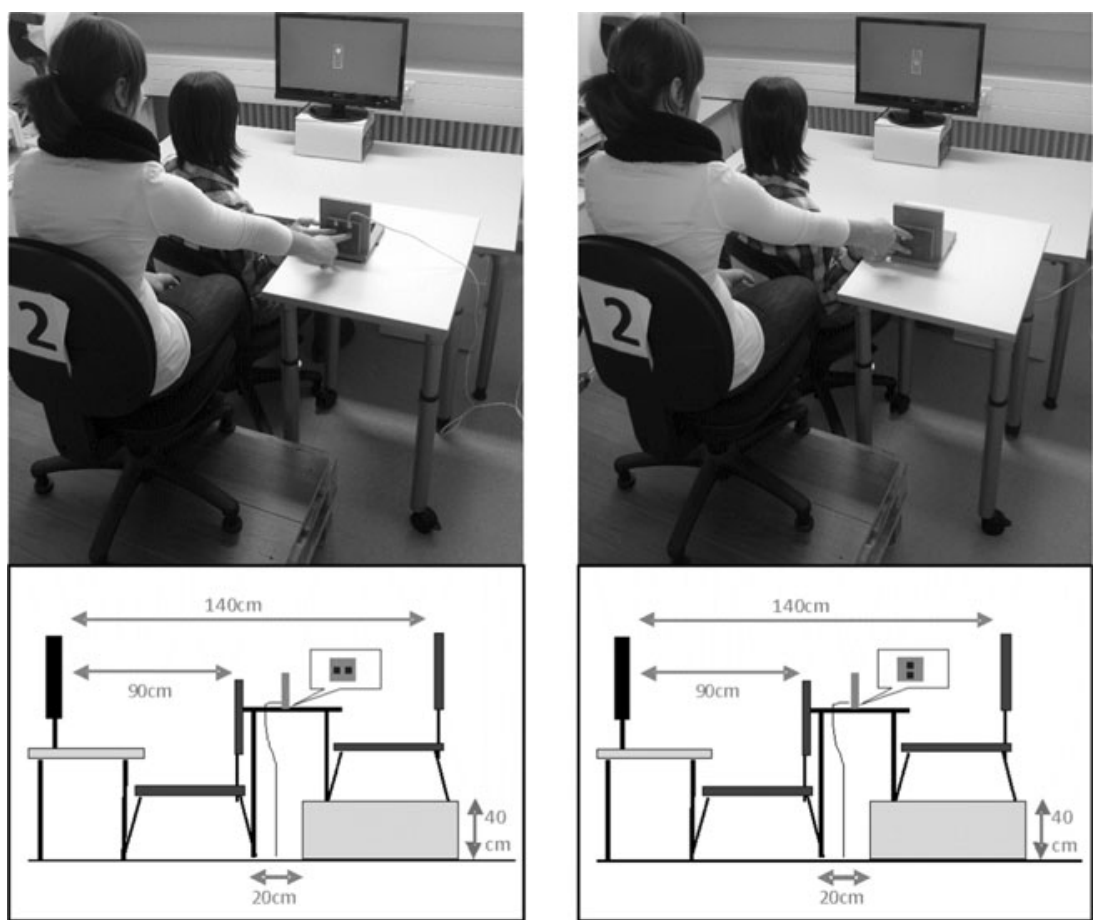

Fig. 2 The experimental setup used in Experiment 2. Participants performed the spatial compatibility task seated in front of and behind each other. The response keys were either horizontally aligned (horizontal condition, left panel) or vertically aligned (vertical condition, right panel) 
Table 2 Experiment 2: Mean response latencies (in milliseconds), error rates (as percentages), and standard deviations for compatible, neutral, and incompatible trials, along with spatial compatibility effects (SCEs: incompatible trials minus compatible trials), as a function of condition

\begin{tabular}{|c|c|c|c|c|c|c|c|c|}
\hline \multirow[b]{3}{*}{ Condition } & \multicolumn{6}{|c|}{ Spatial Compatibility } & & \\
\hline & \multicolumn{2}{|c|}{ Compatible } & \multicolumn{2}{|c|}{ Neutral } & \multicolumn{2}{|c|}{ Incompatible } & \multicolumn{2}{|c|}{ SCE } \\
\hline & $M$ & $S D$ & $M$ & $S D$ & $M$ & $S D$ & $M$ & $S D$ \\
\hline \multicolumn{9}{|c|}{ Response Latencies } \\
\hline Horizontal & 328 & 33 & 319 & 33 & 326 & 30 & -2 & 15 \\
\hline Vertical & 326 & 27 & 316 & 29 & 332 & 29 & $6^{*}$ & 12 \\
\hline \multicolumn{9}{|l|}{ Error Rates } \\
\hline Horizontal & 1.8 & 2.0 & 3.0 & 3.0 & 1.9 & 2.3 & 0.1 & 2.5 \\
\hline Vertical & 2.7 & 2.9 & 3.8 & 4.0 & 3.7 & 3.9 & 1.0 & 3.0 \\
\hline
\end{tabular}

${ }^{*} p<.05$.

Analyses of the error rates revealed a main effect of compatibility, $F(2,92)=4.97, p=.01, \eta_{\mathrm{p}}{ }^{2}=.10$, indicating fewer errors for compatible than for incompatible trials (see Table 2 for details). Follow-up $t$ tests indicated that the joint SCE was neither significant in the horizontal condition, $t<1$, nor in the vertical condition, $t(23)=1.46, p=.16, d=0.30$ (see Table 2). Neither the interaction of compatibility and condition nor the main effect of condition was significant in the analysis of error rates, $F_{\mathrm{s}}<2.2, p \mathrm{~s}>.1$.

\section{Discussion}

Results of Experiment 2 revealed that joint SCEs are only observed if the spatial features of responding agents $\left(R_{\mathrm{A}}\right)$, response keys $\left(R_{\mathrm{K}}\right)$, and stimuli $(S)$ all matched. These results once more contradict the assumption of a shared action/task co-representation account and further extend our knowledge of the process of spatial response coding. As Experiment 1 had already revealed, spatial response coding refers to participants seating alignment. However, not only the spatial relation of coacting participants seems to be taken as spatial reference for coding one's response spatially, but also the spatial alignment of response keys. Thus, the vertical seating alignment of agents that could have induced a spatial response coding as "up" or "down" did not "overwrite" the "left-right" response coding induced by response keys in the horizontal condition, preventing a joint SCE to emerge.

\section{General discussion}

The aim of the present experiments was to provide further empirical evidence for the spatial-coding account as alternative explanation of joint SCEs and to identify the spatial component(s) of joint go/no-go tasks inducing spatial response coding. In our first experiment, we investigated the role of the spatial seating alignment of coacting participants for joint SCEs to emerge. Replicating previous findings (Dittrich et al., 2012), we found no joint SCE when the horizontal seating arrangement did not match the vertical arrangement of response keys and stimuli. Instead, we found a joint SCE only when $S, R_{\mathrm{A}}$, and $R_{\mathrm{K}}$ were all vertically arranged. Supporting previous findings (Philipp \& Prinz, 2010; Wenke et al., 2011), results of Experiment 1 suggest that spatial response coding refers to $R_{\mathrm{A}}$, leading to a joint SCE only if the spatial alignment of $R_{\mathrm{A}}$ and $S$ matches. Thus, (horizontal) seating arrangement seems to counteract a (vertical) $S-\mathrm{R}_{\mathrm{K}}$ overlap. Importantly, the results of Experiment 2 indicate that spatial response coding is influenced by the spatial orientation of seats and keys, thereby crucially extending the dimensional overlap model by Kornblum et al. (1990) in the context of joint action. That is, joint SCEs were only obtained when $S, R_{\mathrm{A}}$, and $R_{\mathrm{K}}$ were all vertically aligned, but not when the vertical arrangement of $S$ and $R_{\mathrm{A}}$ mismatched the orientation of $R_{\mathrm{K}}$ (i.e., $S=R_{\mathrm{A}} \neq R_{\mathrm{K}}$ ).

The present results provide further evidence against the idea of action/task co-representation as a compelling explanation for joint SCEs (Kiernan et al., 2012; Sebanz et al., 2003; Sebanz et al., 2005; Welsh et al., 2013). Given that the action/ task co-representation account proposes that joint SCEs are due to the functionally equivalent representation of one's own and the coactor's action, the dimensional overlap of spatial S$\mathrm{R}$ features in forced two-choice and joint go/no-go tasks should lead to SCEs in both horizontal and vertical versions of spatial compatibility tasks irrespective of the specific (horizontal or vertical) seating alignment of the coactors. However, the finding that a match of only $S$ and $R_{\mathrm{K}}$ is not sufficient for joint SCEs to emerge (i.e., no SCE if $S=R_{\mathrm{K}} \neq$ $R_{\mathrm{A}}$ ) challenges the action/task corepresentation account; rather, the results favor and further specify the spatial-coding account as a comprehensive explanation for joint SCEs. Note, however, although the present results disconfirm the action/task co-representation account in explaining joint SCEs, other joint compatibility effects might provide unbiased measures of action/task co-representation. For example, Atmaca et al. (2011) demonstrated joint compatibility effects in a flanker task. As the flanker task does not include a spatial dimension, this task might provide an unconfounded measure of action/task co-representation (see also Böckler, Knoblich, \& Sebanz, 2012; Liepelt \& Prinz, 2011; Philipp \& Prinz, 2010). Thus, the present work is neither able to nor aims to refute the concept of co-representation in general.

In previous studies supporting the spatial-coding account, it was assumed that the experimental setting of horizontally arranged responses in social and nonsocial go/no-go Simon tasks allows participants to code their responses spatially. In most of these works, the spatial component to which spatial response coding is referred to was either not further specified (Dittrich et al., 2012) or assumed to refer to the orientation of 
response-related action events (Dolk et al., 2011; Dolk, Hommel, et al., 2013). The present experiments specify the spatial-coding account fundamentally in revealing that spatial response coding refers to the spatial arrangement of the response keys $\left(R_{\mathrm{K}}\right)$ and the coacting participants $\left(R_{\mathrm{A}}\right)$, thereby explaining the occurrence of joint SCEs in the vertical conditions of the present experiments as well as joint SCEs in the classical (i.e., horizontal) joint go/no-go task (e.g., Sebanz et al., 2003; Sebanz et al., 2005). In the vertical conditions of Experiments 1 and 2, vertical seating alignment of participants led participants to code their responses as being the upper or being the lower response. Given that response key orientation was also vertically aligned, the spatial features of $R_{\mathrm{K}}$ further strengthened the vertical response coding, explaining the SCEs in these conditions. The same might be true for the classical joint go/no-go task in which $R_{\mathrm{A}}, R_{\mathrm{K}}$, and $S$ are all horizontally aligned. Moreover, these assumptions also explain the missing joint SCE in the horizontal conditions of Experiment 1 and 2. In the horizontal condition of Experiment 1, the seating position led participants to code their responses as left or right, whereas the response keys suggested a vertical response coding. Thus, vertical and horizontal response codes might have canceled each other out, preventing a joint SCE to emerge. In the horizontal condition of Experiment 2, the seating position allowed participants to code their responses as "upper" or "lower" responses; however, this time, the vertical response coding was blurred by a simultaneous horizontal response coding resulting from response key orientation. Interestingly, joint SCEs were completely eliminated in the horizontal conditions of Experiment 1 and 2. This suggests that spatial response coding was to a similar extent influenced by $R_{\mathrm{A}}$ and $R_{\mathrm{K}}$ (if, e.g., spatial response coding were more strongly influenced by $R_{\mathrm{A}}$, one would have expected to find a small but presumably still significant effect in the horizontal condition of Exp. 2, in which $S=R_{\mathrm{A}} \neq R_{\mathrm{K}}$ ). Thus, the present experiments identified two spatial components that both contribute to joint SCEs equally.

So far, we explained the present result pattern with spatial response coding. However, until now little is said about why participants code their responses spatially. In accordance with the theory of event coding (Hommel et al., 2001) Dolk, Hommel, et al. (2013; see also Dolk et al., 2011; Hommel et al., 2009; Liepelt et al., 2011) assumed that participants in joint go/no-go tasks spatially code their responses due to the presence of alternative action events. Thus, to differentiate between the representation of one's own action and the representation of the action performed by the coactor, participants spatially code their action relative to the action of the coactor (i.e., increasing the task relevance of spatial response alternatives through intentional weighing; Memelink \& Hommel, 2013). This discrimination is assumed to be specifically necessary the more similar one's own and other (social or nonsocial) action events are (Dolk, Hommel, et al., 2013). This explanation is not only compatible with the present results but also with several recent findings demonstrating that joint SCEs are influenced by different experimental manipulations of the similarity between self and others such as the interpersonal relationship, the "socialness," or the group membership (Colzato, de Bruijn \& Hommel, 2012; Colzato, Zech, Hommel, Verdonschot, van den Wildenberg, \& Hsieh, 2012; Hommel et al., 2009; Müller, Brass, et al., 2011; Müller, Kühn, van Baaren, Dotsch, Brass, \& Dijksterhuis, 2011; Ruys \& Aarts, 2010; Tsai \& Brass, 2007). For instance, joint SCEs were found to be reduced when participants performed the joint go/no-go task together with an unfriendly coactor or member of the participants' outgroup. Performing a task with an unfriendly coactor or a member of an outgroup might decrease the necessity of differentiating between the representation of one's own and the coactor's action, simply because an unfriendly coactor/coactor belonging to one's outgroup is perceived as being more dissimilar to oneself than a friendly coactor/member of one's ingroup. In other words, the representation of self- and other-generated action events is not necessarily a particular personal trait but rather a consequence of a specific (context-dependent) cognitive state (Colzato, van den Wildenberg, \& Hommel, 2013; Liepelt et al., 2012). Further converging evidence for this assumption comes from a study in which participants performed a joint spatial compatibility task together with a robot (Stenzel et al., 2012). Joint SCEs were observed when the robot was described as human-like; participants presumably perceived the robot's actions as being intentional, evoking representations of other-generated actions that had to be discriminated from the actions performed by participants themselves. Instead, joint SCEs were absent when the robot was described as being passive and deterministic.

In contrast to these modulations of joint SCEs in a rather global (top-down) fashion, more basal task manipulations also affect spatial response coding. For instance, Dittrich et al. (2012) found SCEs in an individual go/no-go task in which participants were required to respond with joystick movements. In this task setting, it appears implausible that participants code their responses spatially to differentiate between action events simply because alternative response events are lacking. Instead, the (left or right) joystick movement itself presumably highlighted the spatial orientation of response alternatives, which, in turn, might have induced spatial response coding. Future research will have to examine if spatial response coding of this basal task manipulation qualitatively differs from spatial response coding observed in the above mentioned joint go/no-go tasks.

Despite the assumption that SCEs in joint go/no-go and forced two-choice tasks are both based on the same basic principle of dimensional overlap, it is obvious that the phenotypes of SCEs differ between both tasks. Most notably, joint SCEs are much smaller than SCEs found in forced two-choice tasks (the SCEs of forced two-choice tasks reported by Dittrich et al., 2012, ranged between 24 and 42 ms, whereas 
joint SCEs ranged between 5 and $6 \mathrm{~ms}$; see also Welsh, 2009; Welsh, Higgins, Ray, \& Weeks, 2007). Dittrich et al. (2012) argued that this difference might be due to the fact that the spatial response dimension is most salient in a forced twochoice task, in which participants are responsible for both left and right response keys. Presumably, referential coding helps not only to discriminate between self and other performed action events (Dolk, Hommel, et al., 2013; Hommel et al., 2009; Liepelt et al., 2011) but it might also be a reasonable mechanism to discriminate between two self-performed action alternatives in forced two-choice tasks (Hommel, 1996a). As both self-performed action alternatives in forced two-choice tasks are more similar than self and other performed action events in joint go/no-go tasks, spatial response coding might be more pronounced in forced two-choice tasks, despite the cognitive demand of controlling two response alternatives, explaining the larger SCE. Based on this assumption, larger joint SCEs might emerge when the spatial attributes of $R_{\mathrm{K}}$ are more salient (e.g., more similar to one's own action events; Dolk, Hommel, et al., 2013) and/or more task-relevant (e.g., by highlighting the spatial features of $R_{\mathrm{K}}$ via instructions). In the present experiments, we avoided the terms "left/right key/ participant" or "up/down key/participant" in order not to induce a spatial response coding via instruction. Systematically varying the impact of spatial response features (thus the task-relevance) by instruction would allow one to examine the influence of this factor on the magnitude of joint SCEs. Moreover, as arbitrary response attributes can be integrated into the representation of responses (e.g., Hommel, 1998; Wenke \& Frensch, 2005), joint SCEs might even emerge in a condition in which the (vertical) response key orientation does not match the (horizontal) stimulus alignment and seating position, if the response keys are labeled as being "left" and "right." A respective examination of the impact of arbitrary response labels would allow one to test whether response codes are a necessary consequence of task settings or whether codes are more flexible in a sense that they are influenced by instructions, a research question that is not answered by the present experiments.

To conclude, the present research provided further evidence for the role of spatial response coding in allowing joint SCEs to occur. Moreover, we scrutinized whether spatial response coding refers to the spatial orientation of response keys, the spatial orientation of responding agents, or both; in fact, spatial response coding is influenced by the spatial orientations of both the responding agents and the response keys, revealing that both have to match with the spatial stimulus dimension in order to find joint SCEs. To further extend our knowledge of cognitive processes underlying single and joint action control, the consideration of this basic mechanism might be useful for future studies investigating S-R compatibility effects, in particular, and joint action, in general.
Author Note K.D., T.D., and A.R.-W. contributed equally to the present work. We thank Lydia Puffe for her assistance in data collection and in preparing the figures.

\section{References}

Atmaca, S., Sebanz, N., Prinz, W., \& Knoblich, G. (2008). Action corepresentation: The joint SNARC effect. Social Neuroscience, 3, 410-420. doi:10.1080/17470910801900908

Atmaca, S., Sebanz, N., \& Knoblich, G. (2011). The joint flanker effect: Sharing tasks with real and imagined co-actors. Experimental Brain Research, 211, 371-385. doi:10.1007/s00221-011-2709-9

Böckler, A., Knoblich, G., \& Sebanz, N. (2012). Effects of a coactor's focus of attention on task performance. Journal of Experimental Psychology. Human Perception and Performance, 38, 1404-1415. doi:10.1037/a0027523

Cohen, J. (1969). Statistical power analysis for the behavioral sciences. San Diego, CA: Academic Press.

Colzato, L. S., de Bruijn, E. R. A., \& Hommel, B. (2012a). Up to "me" or up to "us"? The impact of self-construal priming on cognitive selfother integration. Frontiers in Psychology, 3, 1-4. doi:10.3389/ fpsyg.2012.00341

Colzato, L. S., Zech, H., Hommel, B., Verdonschot, R., van den Wildenberg, W. P. M., \& Hsieh, S. (2012b). Loving-kindness brings loving-kindness: The impact of Buddhism on cognitive self-other integration. Psychonomic Bulletin \& Review, 19, 541-545. doi:10. 3758/s13423-012-0241-y

Colzato, L. S., van den Wildenberg, W. P. M., \& Hommel, B. (2013). Increasing self-other integration through divergent thinking. Psychonomic Bulletin \& Review. doi:10.3758/s13423-013-0413-4

De Jong, R., Liang, C.-C., \& Lauber, E. (1994). Conditional and unconditional automaticity: A dual-process model of effects of spatial stimulus-response correspondence. Journal of Experimental Psychology. Human Perception and Performance, 20, 731-750. doi:10.1037/0096-1523.20.4.731

Dittrich, K., \& Klauer, K. C. (2012). Does ignoring lead to worse evaluations? A new explanation of the stimulus devaluation effect. Cognition \& Emotion, 26, 193-208. doi:10.1080/02699931.2011. 570313

Dittrich, K., Rothe, A., \& Klauer, K. C. (2012). Increased spatial salience in the social Simon task: A response-coding account of spatial compatibility effects. Attention, Perception, \& Psychophysics, 74, 911-929. doi:10.3758/s13414-012-0304-1

Dolk, T., Hommel, B., Colzato, L. S., Schütz-Bosbach, S., Prinz, W., \& Liepelt, R. (2011). How "social" is the social Simon effect? Frontiers in Psychology, 2(84), 1-9. doi:10.3389/fpsyg.2011. 00084

Dolk, T., Liepelt, R., Villringer, A., Prinz, W., \& Ragert, P. (2012). Morphometric gray matter differences of the medial frontal cortex influence the social Simon effect. NeuroImage, 61, 1249-1254. doi:10.1016/j.neuroimage.2012.03.061

Dolk, T., Liepelt, R., Prinz, W., \& Fiehler, K. (2013). Visual experience determines the use of external reference frames in joint action control. PLoS One, 8, e59008. doi:10.1371/journal.pone.0059008

Dolk, T., Hommel, B., Prinz, W., \& Liepelt, R. (2013). The (not so) social Simon effect: A referential coding account. Journal of Experimental Psychology: Human Perception and Performance. doi:10.1037/ a0031031

Eder, A. B., \& Rothermund, K. (2008). When do motor behaviors (mis)match affective stimuli? An evaluative coding view of approach and avoidance reactions. Journal of Experimental Psychology. General, 137, 262-281. doi:10.1037/0096-3445.137. 2.262 
Eimer, M., Hommel, B., \& Prinz, W. (1995). S-R compatibility and response selection. Acta Psychologica, 90, 301-313. doi:10.1016/00016918(95)00022-M

Guagnano, D., Rusconi, E., \& Umiltà, C. A. (2010). Sharing a task or sharing space? On the effect of the confederate in action coding in a detection task. Cognition, 114, 348-355. doi:10.1016/j.cognition. 2009.10.008

Hommel, B. (1996a). S-R compatibility effects without response uncertainty. Quarterly Journal of Experimental Psychology, 49A, 546571. doi:10.1080/713755643

Hommel, B. (1996b). No prevalence of right-left over top-bottom spatial codes. Perception \& Psychophysics, 58, 102-110. doi:10.3758/ BF03205480

Hommel, B. (1998). Automatic stimulus-response translation in dualtask performance. Journal of Experimental Psychology. Human Perception and Performance, 24, 1368-1384. doi:10.1037/00961523.24.5.1368

Hommel, B. (2011). The Simon effect as tool and heuristic. Acta Psychologica, 136, 189-202. doi:10.1016/j.actpsy.2010.04.011

Hommel, B., Müsseler, J., Aschersleben, G., \& Prinz, W. (2001). The theory of event coding (TEC): A framework for perception and action planning. The Behavioral and Brain Sciences, 24, 849-937. doi:10.1017/S0140525X01000103

Hommel, B., Colzato, L. S., \& van den Wildenberg, W. P. M. (2009). How social are task representations? Psychological Science, 20, 794-798. doi:10.1111/j.1467-9280.2009.02367.x

Kiernan, D., Ray, M., \& Welsh, T. N. (2012). Inverting the joint Simon effect by intention. Psychonomic Bulletin \& Review, 19, 914-920. doi:10.3758/s13423-012-0283-1

Knoblich, G., Butterfill, S., \& Sebanz, N. (2011). Psychological research on joint action: theory and data. In B. Ross (Ed.), The psychology of learning and motivation (Vol. 54, pp. 59-101). Burlington, VT: Academic Press.

Kornblum, S., Hasbroucq, T., \& Osman, A. (1990). Dimensional overlap: Cognitive basis for stimulus-response compatibility-A model and taxonomy. Psychological Review, 97, 253-270. doi:10.1037/0033295X.97.2.253

Liepelt, R., \& Prinz, W. (2011). How two share two tasks: Evidence of a social psychological refractory period effect. Experimental Brain Research, 211, 387-396. doi:10.1007/s00221-011-2703-2

Liepelt, R., Wenke, D., Fischer, R., \& Prinz, W. (2011). Trial-to-trial sequential dependencies in a social and non-social Simon task. Psychological Research, 75, 366-375. doi:10.1007/s00426-0100314-3

Liepelt, R., Schneider, J. C., Aichert, D. S., Wöstmann, N., Dehning, S., Möller, H.-J., \& Ettinger, U. (2012). Action blind: Disturbed selfother integration in schizophrenia. Neuropsychologia, 50, 37753780. doi:10.1016/j.neuropsychologia.2012.10.027

Liepelt, R., Wenke, D., \& Fischer, R. (2013). Effects of feature integration in a hands-crossed version of the Social Simon paradigm. Psychological Research, 77, 240-248. doi:10.1007/s00426-012-0425-0

Lu, C.-H., \& Proctor, R. W. (1995). The influence of irrelevant location information on performance: A review of the Simon and spatial Stroop effects. Psychonomic Bulletin \& Review, 2, 174-207. doi:10. 3758/BF03210959

Memelink, J., \& Hommel, B. (2013). Intentional weighting: A basic principle in cognitive control. Psychological Research, 77, 249 259. doi:10.1007/s00426-012-0435-y

Müller, B. C. N., Brass, M., Kühn, S., Tsai, C.-C., Nieuwboer, W., Dijksterhuis, A., \& van Baaren, R. B. (2011). When Pinocchio acts like a human, a wooden hand becomes embodied. Action corepresentation for non-biological agents. Neuropsychologia, 49, 1373-1377. doi:10.1016/j.neuropsychologia.2011.01.022

Müller, B. C. N., Kühn, S., van Baaren, R. B., Dotsch, R., Brass, M., \& Dijksterhuis, A. (2011). Perspective taking eliminates differences in co-representation of out-group members' actions.
Experimental Brain Research, 211, 423-428. doi:10.1007/ s00221-011-2654-7

Philipp, A. M., \& Prinz, W. (2010). Evidence for a role of the responding agent in the joint compatibility effect. Quarterly Journal of Experimental Psychology, 63, 2159-2171. doi:10. 1080/17470211003802426

Prinz, W. (1990). A common coding approach to perception and action. In O. Neumann \& W. Prinz (Eds.), Relationships between perception and action: Current approaches (pp. 167-201). Berlin, Germany: Springer.

Prinz, W. (1997). Perception and action planning. European Journal of Cognitive Psychology, 9, 129-154. doi:10.1080/713752551

Prinz, W. (2012). Open minds: The social making of agency and intentionality. Cambridge, MA: MIT Press.

Proctor, R. W., Vu, K.-P. L., \& Nicoletti, R. (2003). Does right-left prevalence occur for the Simon effect? Perception \& Psychophysics, 65, 1318-1329. doi:10.3758/BF03194855

Ruys, K. I., \& Aarts, H. (2010). When competition merges people's behavior: Interdependency activates shared action representations. Journal of Experimental Social Psychology, 46, 1130-1133. doi:10. 1016/j.jesp.2010.05.016

Sebanz, N., Knoblich, G., \& Prinz, W. (2003). Representing others' actions: Just like one's own? Cognition, 88, B11-B21. doi:10. 1016/S0010-0277(03)00043-X

Sebanz, N., Knoblich, G., \& Prinz, W. (2005). How two share a task: Corepresenting stimulus-response mappings. Journal of Experimental Psychology. Human Perception and Performance, 31, 1234-1246. doi:10.1037/0096-1523.31.6.1234

Sebanz, N., Bekkering, H., \& Knoblich, G. (2006). Joint action: Bodies and minds moving together. Trends in Cognitive Sciences, 10, 7076. doi:10.1016/j.tics.2005.12.009

Shiu, L. P., \& Kornblum, S. (1999). Stimulus-response compatibility effects in go-no-go tasks: A dimensional overlap account. Perception \& Psychophysics, 61, 1613-1623. doi:10.3758/BF03213122

Simon, J. R. (1969). Reactions toward the source of stimulation. Journal of Experimental Psychology, 81, 174-176. doi:10.1037/h0027448

Simon, J. R. (1990). The effects of an irrelevant directional cue on human information processing. In R. W. Proctor \& T. G. Reeve (Eds.), Stimulus-response compatibility: An integrated perspective (pp. 31-86). Amsterdam, The Netherlands: North-Holland.

Stenzel, A., Chinellato, E., Tirado Bou, M. A., del Pobil, Á. P., Lappe, M., \& Liepelt, R. (2012). When humanoid robots become human-like interaction partners: Corepresentation of robotic actions. Journal of Experimental Psychology. Human Perception and Performance, 38, 1073-1077. doi:10.1037/a0029493

Tsai, C.-C., \& Brass, M. (2007). Does the human motor system simulate Pinocchio's actions? Coacting with a human hand versus a wooden hand in a dyadic interaction. Psychological Science, 18, 1058-1062. doi:10.1111/j.1467-9280.2007.02025.x

Tsai, C.-C., Kuo, W.-J., Jing, J.-T., Hung, D. L., \& Tzeng, O. J.-L. (2006). A common coding framework in self-other interaction: Evidence from joint action task. Experimental Brain Research, 175, 353-362. doi:10.1007/s00221-006-0557-9

Tsai, C.-C., Kuo, W.-J., Hung, D. L., \& Tzeng, O. J. L. (2008). Action corepresentation is tuned to other humans. Journal of Cognitive Neuroscience, 20, 2015-2024. doi:10.1162/jocn.2008.20144

Vesper, C., Butterfill, S., Knoblich, G., \& Sebanz, N. (2010). A minimal architecture for joint action. Neural Networks, 23, 998-1003. doi:10.1016/j.neunet.2010.06.002

Vu, K.-P. L., Proctor, R. W., \& Pick, D. F. (2000). Vertical versus horizontal spatial compatibility: Right-left prevalence with bimanual responses. Psychological Research, 64, 25-40. doi:10.1007/ s004260000035

Vu, K.-P. L., Pellicano, A., \& Proctor, R. W. (2005). No overall right-left prevalence for horizontal and vertical Simon effects. Perception \& Psychophysics, 67, 929-938. doi:10.3758/BF03193544 
Welsh, T. N. (2009). When $1+1=1$ : The unification of independent actors revealed through joint Simon effects in crossed and uncrossed effector conditions. Human Movement Science, 28, 726-737. doi:10.1016/j.humov.2009.07.006

Welsh, T. N., Higgins, L., Ray, M., \& Weeks, D. J. (2007). Seeing vs. believing: Is believing sufficient to activate the processes of response co-representation? Human Movement Science, 26, 853866. doi:10.1016/j.humov.2007.06.003

Welsh, T. N., Kiernan, D., Neyedli, H. F., Ray, M., Pratt, J., Potruff, A., \& Weeks, D. J. (2013). Joint Simon effects in extrapersonal space.
Journal of Motor Behavior, 45, 1-5. doi:10.1080/00222895.2012. 746635

Wenke, D., \& Frensch, P. A. (2005). The influence of task instruction on action coding: Constraint setting or direct coding? Journal of Experimental Psychology. Human Perception and Performance, 31, 803-819. doi:10.1037/0096-1523.31.4.803

Wenke, D., Atmaca, S., Holländer, A., Liepelt, R., Baess, P., \& Prinz, W. (2011). What is shared in joint action? Issues of co-representation, response conflict, and agent identification. Review of Philosophy and Psychology, 2, 147-172. doi:10.1007/s13164-011-0057-0 